\title{
A GIS-Based Analysis of Earth's Crust Temperature at Depth for Geothermal Energy Exploration in Afghanistan
}

\author{
Mohammad Abed Anwarzai and Ken Nagasaka
}

\begin{abstract}
The future green world, without of greenhouse gases, is possible to produce the electricity from the renewable energy resources. The geothermal is one of the most potential clean energy sources to be developed in the next century. The geothermal energy potential study needs the temperature value and amount of stored heat in the underground rocks. The purpose of this research is to determine the earth's crust temperature at the depth of 3.5 to $10.5 \mathrm{~km}$ for geothermal energy potential calculation in Afghanistan. The temperature at depth prediction model is based on the tectonic ages, tectonic activity, geological structures, and hot spring data. To achieve this goal, in GIS, the earth's crust thickness, sediment thickness, surface heat flow, mantle heat flow, and surface temperature have been mapped. The temperature calculation formulas, as a function of depth, were applied in GIS model to estimate the temperature at depth. The analysis contains the sediment and basement contribution along with surface temperature correction considering the constant thermal conductivity and radioactive heat generation in the crust. The resulting maps are plotted for each $\mathrm{km}$ of depths from 3.5 to $10.5 \mathrm{~km}$. The calculation result is in the range of; minimum $39^{\circ} \mathrm{C}$ and maximum $347^{\circ} \mathrm{C}$ average temperature at the depth of $3.5 \mathrm{~km}$ and $10.5 \mathrm{~km}$ respectively. The huge geothermal energy (power production) is available; First in Helmand, Kandahar, and Herat provinces, moreover, in northern and eastern deeper sedimentary region of the country at the depth of $3.5 \mathrm{~km}$. Second in the all known geothermal fields of the country until the depth of $5 \mathrm{~km}$.
\end{abstract}

Index Terms-Afghanistan, geothermal energy, earth's crust temperature, geographical information system.

\section{INTRODUCTION}

The earth has a layered structure that is; crust (Oceanic and continental), lithosphere, asthenosphere, mantle (upper and lower), and core (outer and inner). $99 \%$ volume of the planet is hotter than $1000^{\circ} \mathrm{C}$, and almost $0.1 \%$ is colder than $100^{\circ} \mathrm{C}$. The temperature and pressure of inner core (at a depth of $6000 \mathrm{~km}$ ) are above $5000^{\circ} \mathrm{C}$ and $400 \mathrm{GPa}$ respectively, while the earth surface average temperature is around $14^{\circ} \mathrm{C}$ [1]. This difference in the temperature creates heat flow from the mantle to the surface of the earth and stored heat in the earth's crust is called geothermal energy. Understanding heat flow value is one of the required parameters for crust temperature analysis. According to the plate's tectonic history, that Afghan's land was created in the collision process of Eurasian and Indian plates at the end of Cretaceous (65 million years ago). In consequence, there is an enormous

Manuscript received September 3, 2017; revised December 3, 2017.

The authors are with the Department of Electronic and Information Engineering, Tokyo University of Agriculture and Technology, 2-24-16, Nakacho, Koganei-shi, Tokyo, 184-8588, Japan (e-mail: abedafg@hotmail.com, bahman@cc.tuat.ac.jp). stress on the geostructures of the country from the south (Indian plate) and generate huge fractional and seismic heat energy in the Afghan crust [2]. Mostly, along with the major fault zones. The Fig. 1 illustrates the earth's crust thickness, significant faults, hydrothermal, hot spring and volcanic dome locations. The extrapolated crust thickness from world crust thickness data has relation to the topography of the land that is the earth's crust thickness increasing in the mountainous areas. It also presents the sign of collision of Indian and Eurasian plates, and neotectonic activity, in which resulted in the uplift of Hindukush and decreasing of the terrain altitude from NE-SW, the same decrease can be seen in the crust thickness from NE-SW. The location of geothermal energy resources in Afghanistan also has relation with old volcanos and intrusive rocks; there are more than 50 volcanic domes (all of them are not shown on the map) in central and southwestern Afghanistan [2]. The largest faults and hundreds of other faults in the country divide and weak the earth's crust and caused the earthquakes and huge thermal energy release to the crust. In result, the stored heat in the crust has relation with seismic activity. Though, the active seismic hazard region in the country is the northeastern part along with the Chaman Maqur fault. The majority of Hotsprings and surface manifestation of hydrothermal can be seen around the faults they are located from the joint of faults (in Salang) toward the southwest (Hilmand) and west (Herat) of the country.

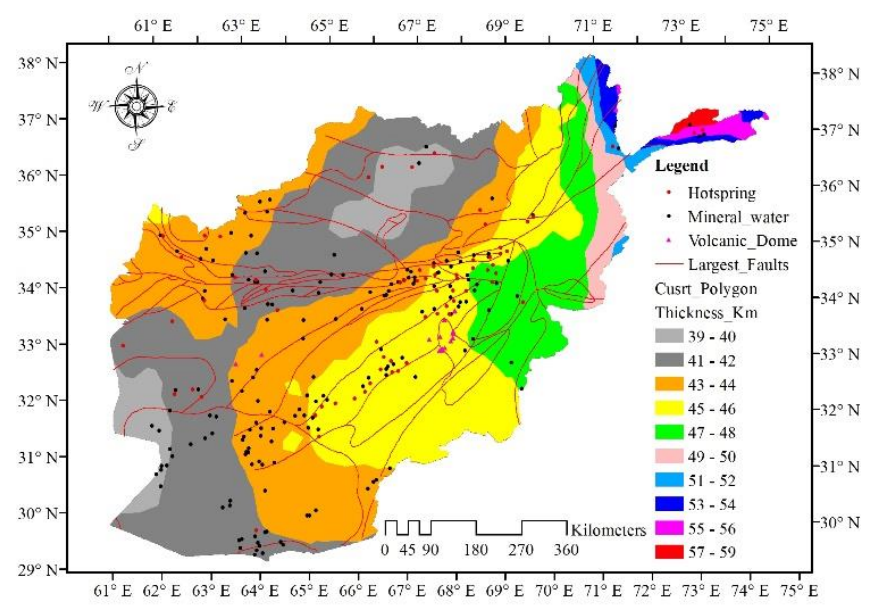

Fig. 1. Earth's crust thickness, active faults, volcanic domes, and thermal mineral water in Afghanistan [3]-[7].

So far there are no any countrywide measurements available regarding geothermal energy such as groundwater temperature, heat flow, thermal conductivity, radioactive heat generation and other required parameters to estimate the crust temperature. Alternatively, it is possible to make a reasonable model of temperature estimation on the base of tectonic ages, tectonic activity, geostructures, and hot spring 
data. The geothermal studies in the country are limited to; the hydrological atlas of Faryab province [8]. The Curie point $\left(580^{\circ} \mathrm{C}\right)$ depth and heat flow estimation in the west of Afghanistan from the aeromagnetic data [9]. The prospect area mapping for geothermal energy exploration in Afghanistan [10]. We have used the available data to estimate the earth's crust temperature. The purpose of this research is to determine the earth's crust temperature until $10 \mathrm{~km}$ depth for hydrothermal and EGS (Enhanced Geothermal Systems) development in Afghanistan. The temperature has been calculated in sediment and basement layers separately by GIS tools. The surface heat flow was estimated in empirical predictors by geological ages and geological settings in GIS with the multi criteria decision analysis system [11]. The estimated temperature at depth, sediment thickness, mantle heat flow, and surface temperature (including hot springs) mappings, method and results have been explained in detail as follows.

\section{Calculation Method}

The temperature at depth calculation covers the temperature estimation from the surface to $5 \mathrm{~km}$ for hydrothermal and beyond $5 \mathrm{~km}$ for EGS exploration. Fig. 2 illustrates the calculation process of earth's crust temperature. Many GIS tools were used to map the required input layers first. The overlay union tool of GIS was used to combine the input layers for average temperature estimation in the geographical grid. The earth's crust temperature maps at depth have been estimated by surface temperature, heat flow (surface and mantle), thermal conductivity, and radioactive heat generation in both sediment and basement layers according to the following equations;

$$
T_{\text {final }}=T+T_{0}
$$

where $T_{0}$ is the surface temperature such as water well and springs including hot springs temperature, $T$ is the calculated temperature at depth, it can be estimated in the sediment and basement layers as in the following equations;

$$
\begin{gathered}
T=T_{s}+T_{b} \\
T_{s}=\frac{Q_{0} * X_{S}}{K_{S}}-A_{s} \frac{X_{s}^{2}}{K_{s}} \\
T_{b}=\frac{Q_{m} * X_{b}}{K_{b}}-A_{b} r^{2}\left[\frac{1-e^{\frac{-X_{b}}{r}}}{K_{b}}\right]
\end{gathered}
$$

where the $s$ and $b$ subscripts are for sediment and basement layers contribution. $Q_{0}$ is the surface measured or estimated heat flow. $Q_{m}$ is the mantle heat flow, $K$ is thermal conductivity, $X$ is the thickness of the considered layer such as $3.5,4.5 \ldots 10.5 \mathrm{~km}, A$ is radioactive heat generation amount in the crust, and $r$ is the radioactive depth variable (the thickness of the radioactivity layer) [12].

The relevant parameters are sediment thickness, surface heat flow, mantle heat flow, radioactivity layer thickness, radiogenic heat generation, thermal conductivity, and earth surface temperature. The appropriate understanding of these contributors in each grid could play a significant role in the accuracy of the temperature analysis. Therefore, they are analyzed in the following sections in details.

\section{A. Radioactive Components and Thermal Conductivity}

The surface heat flow is the summation of; heat flow from the mantle and generated heat in the crust due to the decay of radioactive elements such as Uranium, Potassium, and Thorium. It leads the temperature distribution in the crust to be dependent on the vertical conductivity of the rocks, and radioactive heat generation in the rocks. Right now, the field measurement of these two parameters for each grid in the calculation is not available. We have used the general thermal conductivity value $\left(2.5 \mathrm{~W} / \mathrm{m}^{\circ} \mathrm{C}\right)$ for Afghanistan [1], [9]. Regarding radioactivity thickness and heat generation in the crust, we have considered the radioactivity heat generation measurement of Kohistan in Pakistan, due to geological similarity. These measurements were done in rocks using gamma-ray spectrometry; the study revealed that the radioactive heat generation value is higher in lower density rocks than higher density rocks and depends on lithology of the rocks [13]. Therefore, we also have assumed the decay of radioactive elements layer thickness in the crust to be until 10 $\mathrm{km}$ in areas have sediment thickness less than $3 \mathrm{~km}$ and $\left(13000-X_{s}\right)$ in areas having deeper thickness than $3 \mathrm{~km}[14]$. Moreover, the measured radioactive generation values were in the range of $0 \sim 2.73 \mu \mathrm{W} / \mathrm{m}^{3}$, we also have used a constant value of $1.15 \mu \mathrm{W} / \mathrm{m}^{3}$ in this calculation.

\section{B. Sediment Thickness in Afghanistan}

The sediment layer is the earth surface structure which is transferred by water, ice and wind. The globally estimated sediment thickness in Afghanistan are from 10 to 9000 meters. There are few studies regarding sediment thickness in Afghanistan until now. We have used them together to map the sediment thickness in the entire country. First the estimated sediment thickness in Afghanistan from air born anomalies [15]. The estimated sediment thickness from the air born data almost cover the whole country, except the central and northeastern mountainous regions (Baba mountain and Hindukush), where the airborne survey was not possible due to high terrain. This sediment thickness from air born data also has been confirmed by another study regarding Afghanistan geostructures. The study of the power spectrum of magnetic and gravity data reveal the sediment thickness in general from 1 to $1.5 \mathrm{~km}$ in southwest of Afghanistan which is in agreement with calculated sediment thickness data [16] that we received for this study. We have received the estimated sediment XYZ data, from the author, the thickness is from 1 to 5920 meters, cover the area where the air born survey was possible. To map the sediment thickness in entire country, we have used the global 1x1 degree grid [17] and estimated sediment thickness from airborne data together as in the following steps;

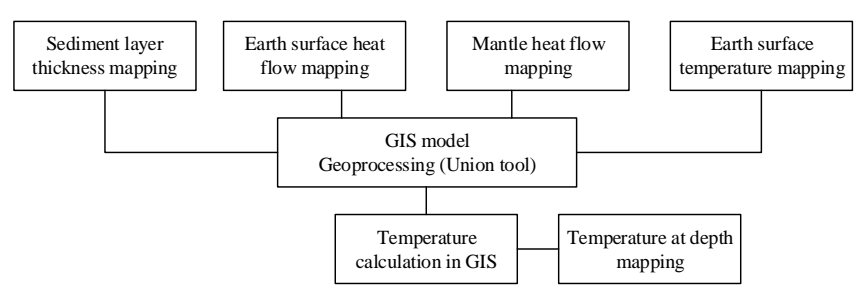

Fig. 2. Temperature at depth calculation process. 
Step 1: The estimated sediment from air born points are plotted in GIS, the negative to 0 values were removed from the analysis.

Step 2: Global sediment thickness points cover the country and around areas are plotted in the $1 \times 1$ degree $(91 \times 112) \mathrm{km}$ grid:

- IDW (Inverse Distance Weighted) interpolation was used to predict the $(3.1 \times 4) \mathrm{km}$ grid resolution sediment thickness in the raster.

- Conversion tool (Raster to point) was used to convert the interpolation output in raster to the points

- Selection quires were applied, to remove the points they are; out of country boundary, and areas contain the predicted sediment thickness from air born data.

Step 3: the global and estimated from air born sediment thickness data were merged to map the sediment thickness in the whole country. The resulting layer was points, for polygon layer, we used the conversion tools of GIS;

- Point to raster tool to convert the points to the raster.

- Raster to a polygon to achieve the sediment thickness map in polygons.

The sediment thickness mapping result has been plotted in Fig. 3; the possible thickness would be from 10 to 8970 meters. The deepest sediment thickness can be seen in northern part of the country; the second would be possible in the east of Afghanistan. The lowest sediment thickness would be possible in the high altitude areas such as northeastern and central mountainous topography.

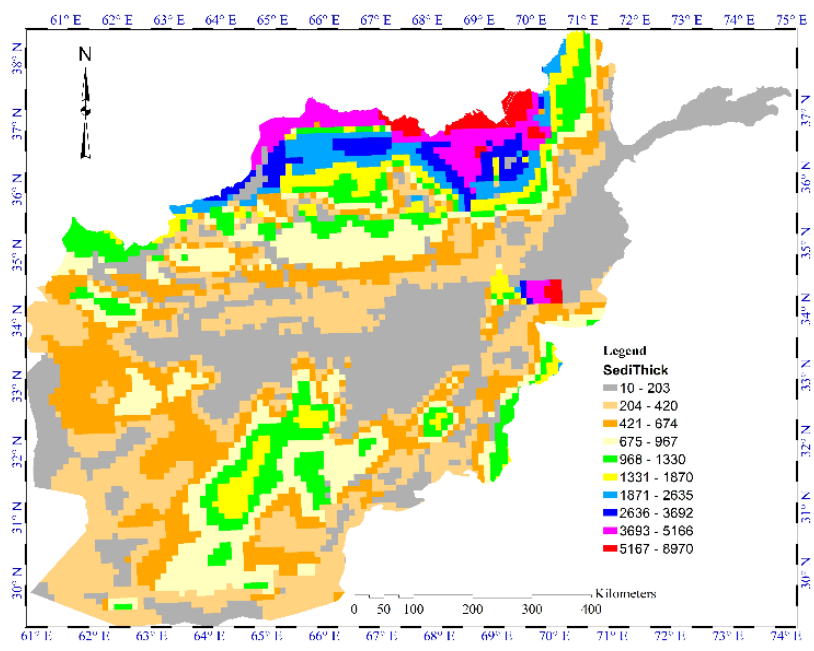

Fig. 3. Thickness of sediment layer in meters.

\section{Surface Heat Flow}

The field measurement of earth surface heat flow in the country is not available. It is one of the required parameters for temperature calculation in the sediment layer. We had estimated the earth surface mean heat flow value by thermo-tectonic age and geological setting in GIS using multi criteria decision analysis (MCDA) system [10]. The global, continental heat flow mean value has a correlation with thermo-tectonic age. That is the mean heat flow decline with age increasing. The highest surface heat flow could be observed in Cenozoic era displaced igneous, Mesozoic orogeny, and carboniferous bodies. In the result, the earth surface heat flow is higher in the intrusive rocks and geothermally potential areas such as hot spring, hydrothermal mineral waters, faults system, geopressured and petroleum.
Therefore, we have designed the GIS model and MCDA system to distinguish the prospect high and low heat flow regions in the same geological ages. The global [18], Eurasia [19], and Asia [20] mean heat flow value was used to determine the intrusive, prospect high and low heat flow curves as a function of geological time in MS Excel. The trend line of curve fitting was used to define the heat flow estimation equations for intrusive bodies, prospect high and low heat flow areas. In general, the earth surface heat flow is higher in the thermally suitable areas. For instance, the heat flow map of Akita and Iwate in Japan [21] displays that the heat flow values are higher in the regions, geologically, geochemically, and geophysical suitable for geothermal energy exploitations. These suitable areas for geothermal energy exploration in the country have been considered having higher heat flow values such as the areas: $4000 \mathrm{~m}$ around the hot springs and hydrothermal mineral waters, $5000 \mathrm{~m}$ around largest and active faults, $1000 \mathrm{~m}$ around the secondary faults, petroleum and gas prospect, geopressured, and intrusive rock areas. Then we had applied these empirical estimators in GIS to determine the heat flow values for intrusive rocks, prospect high heat flow zones, and low heat flow areas. The predicted mean heat flow values are in the range of 43.6 to $108.8 \mathrm{~mW} / \mathrm{m}^{2}$. Fig. 4 shows the estimated surface heat flow map for Afghanistan. The highest surface heat flow could be possible in the Cenozoic intrusive rocks area, around active faults, hot springs, hydrothermal mineral waters, geopressured and petroleum regions located in a Cenozoic and Mesozoic era with mean heat flow value above $70 \mathrm{~mW} / \mathrm{m}^{2}$

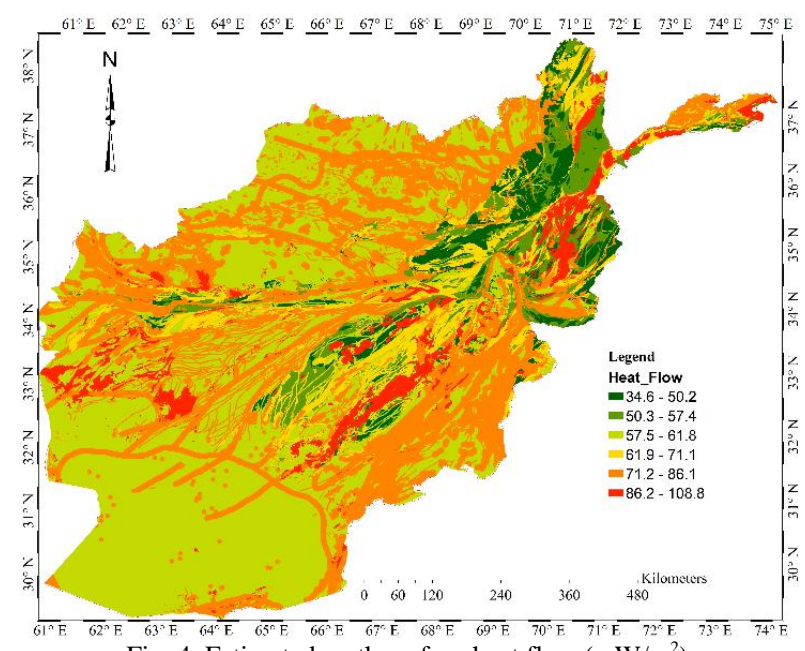

Fig. 4. Estimated earth surface heat flow $\left(\mathrm{mW} / \mathrm{m}^{2}\right)$.

\section{Mantle Heat Flow}

The earth surface average temperature is $14^{\circ} \mathrm{C}$, and the core mantle boundary temperature is around $3000^{\circ} \mathrm{C}$. This difference of temperature is the driving force for the heat flow from the hot interior to the cold surface. There are several contributors in the surface heat flow values, only $30 \%$ is related to the hot core flow, which is called Fourier conduction. $70 \%$ is generated from radioactive elements of the earth's crust such as uranium, thorium, and potassium [1]. The exact amount of mantle heat flow to the earth's crust is unknown. The mantle heat flux has a correlation with surface heat flow. For instance, in the stable continental area, the mean surface heat flow is less than $55 \mathrm{~mW} / \mathrm{m}^{2}$, only around 
$15 \mathrm{~mW} / \mathrm{m}^{2}$ is from the mantle and the rest comes from the crustal radioactive heat production. In extensional areas, the heat flow higher than $75 \mathrm{~mW} / \mathrm{m}^{2}$ contribute the radioactive heat generation and almost $30 \mathrm{~mW} / \mathrm{m}^{2}$ from the mantle [22]. In Afghanistan, where the earth's crust is not stable, the major faults such as Panjsher-Herat E-W strike-slip fault depth is around $700 \mathrm{~km}$ to the mantle and provide the thermal circulation to the crust [2]. Therefore, the mantle heat flow in the crust could be different according to the geostructures. We have used two methods to calculate the possible mantle heat flow in the Afghan land crust.

First, from the surface heat flow; the mantle heat flow $\left(Q_{m}\right)$ has relation with measured heat flow below the sediment $\left(Q_{s}\right)$ as in the following equation.

$$
Q_{m}=Q_{s}-A_{b} * r
$$

where $Q_{s}$ measurement is also not available, using the same approach, we can determine the heat flow bellow of the sediment as in the following.

$$
Q_{s}=Q_{0}-A_{s} * X_{s}
$$

Finally, the mantle and surface heat flow relation can be written as in the following equation.

$$
Q_{m}=Q_{0}-A_{s} * X_{s}-A_{b} * r
$$

where, $Q_{0}$ is the estimated mean surface heat flow from 34.6 to $108.8 \mathrm{~mW} / \mathrm{m}^{2}$, the radioactive heat generation in the sediment and basement are supposed to be same $\left(A_{s}=A_{b}=\right.$ $\left.1.15 \mu \mathrm{W} / \mathrm{m}^{3}\right), \mathrm{X}_{\mathrm{s}}$ is the sediment thickness in Afghanistan from 10 to 8970 meters, the radioactive heat generation layer depth $(r)$ supposed to be $10 \mathrm{~km}$ in the area has sediment thickness $\left(X_{s}\right)$ less than $3 \mathrm{~km}$, else $\left(r=13000-X_{s}\right)$ [12]. At a result, the estimated mantle heat flow would be in the range of 22 to $97 \mathrm{~mW} / \mathrm{m}^{2}$.

Second from the Curie point temperature; the Curie point $\left(580^{\circ} \mathrm{C}\right)$ depth had been estimated in southwest of Afghanistan from Aeromagnetic data [9]. This temperature would be located in the range of 13 to $45 \mathrm{~km}$ depths. We have used the steady-state condition, no advection, the Fourier law with a constant thermal conductivity and radioactive heat production, the temperature at depth profile can be written as in the following [23].

$$
T_{z}=\frac{-A}{2 K} z^{2}+\frac{Q_{m}+A * h}{K} z+T_{0}
$$

where $h$ is the earth's crust thickness from 39 to $45 \mathrm{~km}$ in the western Afghanistan), $T_{z}$ is the $580^{\circ} \mathrm{C}$ temperature at depth $\mathrm{z}$ (CPD), and surface temperature assumed $10.5^{\circ} \mathrm{C}$, then the mantle heat flow $\left(Q_{m}\right)$ can be written;

$$
Q_{m}=\frac{569.5 * K}{C P D}-A *\left(h-\frac{C P D}{2}\right)
$$

The result of mantle heat flow calculation in the western crust from the CPD values reveal the mantle heat flow would be in the range of 6 to $66 \mathrm{~mW} / \mathrm{m}^{2}$. In the comparison of both maps and calculation, we also have considered the mantle heat flow $60 \mathrm{~mW} / \mathrm{m}^{2}$ in the hotter crust such as shallow CPD, major faults, intrusive rocks, petroleum and geopressured regions, otherwise $35 \mathrm{~mW} / \mathrm{m}^{2}$ [12] as it has been shown in (Fig. 5).

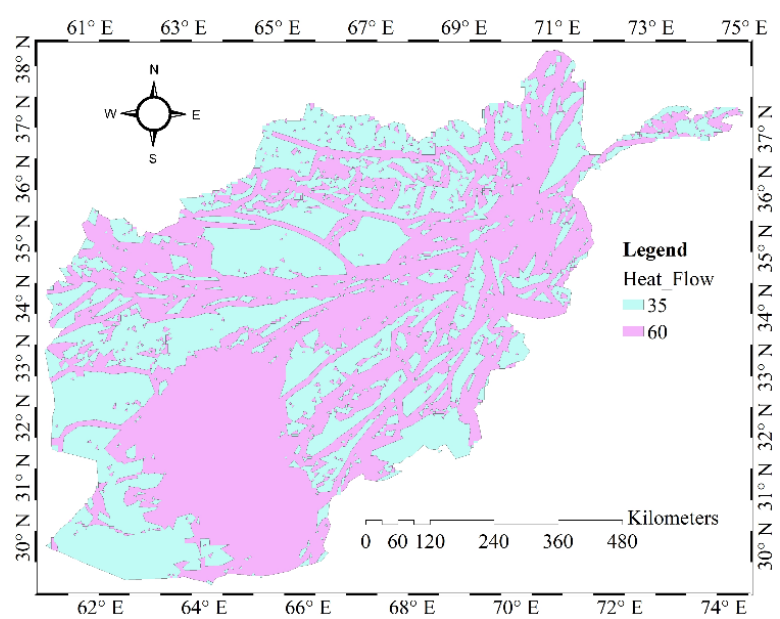

Fig. 5. Mantle heat flow $\left(\mathrm{mW} / \mathrm{m}^{2}\right)$ map of Afghanistan.

\section{E. Earth Surface (Groundwater) Temperature}

The earth surface temperature has been estimated from the groundwater temperature measurements in the country. The average air temperature controls the shallow subsurface temperature; such as, at a depth of few meters the earth subsurface cool down and warm up with seasonal temperature variation. However, the ground temperature would be constant at the depth of 6 to 10 meters. Until now, the publicly available data of ground temperature are;

69 Hotsprings, as depicted in Fig. 1, has been downloaded from the NREL data for Afghanistan [4]. The temperatures are above $25^{\circ} \mathrm{C}$; the highest is $55^{\circ} \mathrm{C}$ in Chah Ganj of Balkh and Sarab of Baghlan provinces.

174 hydrothermal mineral water springs and wells temperature data from the department of Geological Exploration \& Mineral Extraction, Kabul Polytechnic University [5]. The hydrothermal mineral water data were mapped in GIS; recorded temperatures are between 9 to $70^{\circ} \mathrm{C}$.

Hydrological Atlas of Faryab province, thermogeology (chapter 7) reported the shallow subsurface temperature by measurements of ground waters in 2013 [8]. The study carried out in 33 drilled boreholes, 67 springs, and 335 dug wells, totally 435 points in 9 districts of Faryab province. The recorded temperature range is from 10 to $26.6{ }^{\circ} \mathrm{C}$. In the result; there is a correlation between ground temperature value and elevation above the sea level. The best fitted linear regression shows approximately $0.5{ }^{\circ} \mathrm{C} / \mathrm{m}$ lapse rate in Faryab with an equation as follows [8];

$$
\text { Temp }=21.2^{\circ} \mathrm{C}-0.00488^{\circ} \mathrm{C} / \mathrm{m} * \text { Elevation }
$$

We have used the Afghanistan Elevation shapefile from NREL [4] in GIS to apply the Eq.10 for the determining of possible groundwater temperature by assuming the constant temperature $\left(4^{\circ} \mathrm{C}\right)$ in the regions having altitude higher than 3500 meters. The estimated ground average temperature would be in the range of 4 to $20^{\circ} \mathrm{C}$. In the following steps, the earth surface temperature map has been plotted in GIS considering the estimated average temperature, Hotsprings, and hydrothermal mineral water data; 
- Estimated ground water's temperature $4 \sim 20{ }^{\circ} \mathrm{C}$ polygon was converted to the raster $(1 \mathrm{x} 1) \mathrm{km}$ grid by conversion tool (Polygon to raster).

- Resulted raster converted to the points by conversion tool (Raster to points).

- Geoprocessing tool (Merge) was used to combine the Hotsprings, hydrothermal mineral water, and estimated ground temperature data, the possible temperature range of result map is $4 \sim 70{ }^{\circ} \mathrm{C}$.

- Conversion tool (Point to raster) was used to convert the merged points to the raster (1x1) km grid.

- Conversion tool (Raster to polygon) was used to convert the obtained raster to the ground temperature polygon for further analysis.

The Fig. 6 shows the earth surface (groundwater) temperature in Afghanistan. The 21 to $70{ }^{\circ} \mathrm{C}$ displays the hot spring locations. The earth surface temperature estimation has been confirmed with Chakari of Kabul data such as in map the calculated temperature range is $10 \sim 13.5^{\circ} \mathrm{C}$, and the field measurement was $10.8 \sim 15.5^{\circ} \mathrm{C}$ [24].

\section{F. GIS Model and Temperature Calculation}

The sediment thickness, surface heat flow, mantle heat flow and earth surface temperature had been mapped individually as explained in above sections. In GIS model the overly tool of the union was used to combine the input maps for temperature calculation on the base of geographical areas. In the attribute table of union result map, the new columns were added for constant values and temperature at depth calculation. The constant values of thermal conductivity and radioactivity were assumed for sediment and basement layers. $\left(K_{s}=K_{b}=2.5 \mathrm{~W} / \mathrm{m}^{\circ} \mathrm{C}\right.$, and $\left.A_{s}=A_{b}=1.15 \mu \mathrm{W} / \mathrm{m}^{3}\right)$.

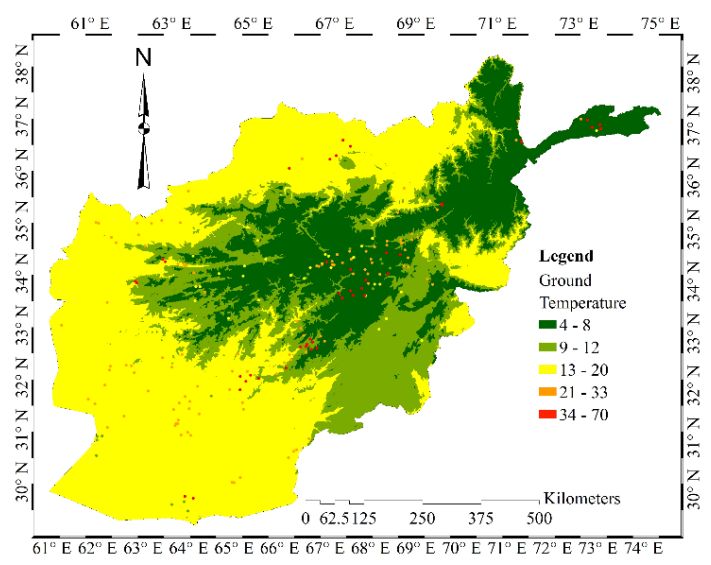

Fig. 6. Earth surface (Groundwater) temperature in ${ }^{\circ} \mathrm{C}$.

For temperature calculation, the field calculator in attribute table was used to estimate the temperature at depth in the following steps;

1) Areas having sediment thickness less than $3 \mathrm{~km}$. The equations 1 to 4 were applied with radioactivity layer thickness value $(r=10,000 \mathrm{~m})$.

2) Areas have sediment thickness more than $3 \mathrm{~km}$;

- If sediment thickness is more than the calculation depths value $\left(3,000 m<\mathrm{X}_{\mathrm{s}} \geq X_{d}\right)$, where $X_{d}$ is from 3.5 to $10.5 \mathrm{~km}$, the only sediment section equation with surface correction $\left(T_{\text {final }}=T_{s}+T_{0}\right)$ were applied.

- If sediment thickness is less than the calculation depth value $\left(3,000 m<X_{s}<X_{d}\right)$ then the equations 1 to 4 were used with radioactivity layer thickness value;

$$
\left(r=13,0000-X_{s}\right)
$$

The result maps have been plotted in the following section.

\section{RESULT}

The minimum possible average temperature at depth 3.5 $\mathrm{km}$ would be $39^{\circ} \mathrm{C}$ and maximum until $165^{\circ} \mathrm{C}$ as can be seen in Fig. 7. The temperature above $90^{\circ} \mathrm{C}$ is reasonable for geothermal power plants generation. According to this study, the $144,105 \mathrm{~km}^{2}$ and $447,567 \mathrm{~km}^{2}$ areas may have a temperature above $90^{\circ} \mathrm{C}$ in the depths of $3.5 \mathrm{~km}$ and $4.5 \mathrm{~km}$ respectively. The areas have more sediment thickness will have higher earth's crust temperature such as in north and east of Afghanistan. In general, the earth's crust temperature may be higher around fault systems, hot springs, intrusive rocks, petroleum and geopressured regions. They are more prospect areas for geothermal energy exploitation. Fig. 8 displays the average temperature at the depth of $4.5 \mathrm{~km}$. In this depth the power production would be possible in all geothermal fields of the country, the higher temperature (126 205) ${ }^{\circ} \mathrm{C}$ could be observed; in northern sedimentary Amu basin (Takhar to Faryab), especially, around the fault systems, petroleum, geopressured and hot spring areas. In east at the Kabul basin (Surobi to Chaparhar and Hisarak to Mihtarlam). In Kandahar along the Arghandab basin (ShahWli Kot to Maywand). These regions are located near to the capital Kabul, big cities (such as Kandahar, Herat, Mazar, and Jalalabad), and to the existing power system. Moreover around the all hot springs of the country. Fig. 9 shows, in the depth of $5.5 \mathrm{~km}$, the average temperature would be higher than $110^{\circ} \mathrm{C}$ in the entire country geothermal prospect areas.

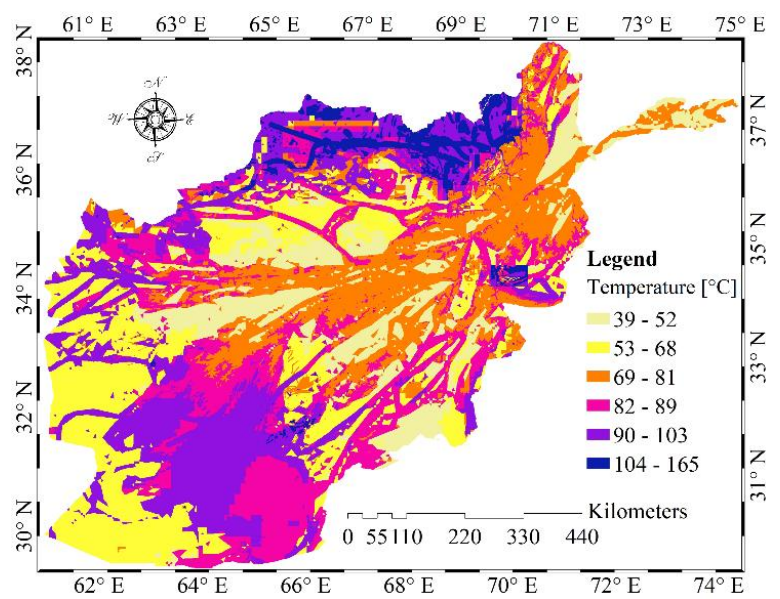

Fig. 7. Earth's crust average temperature at $3.5 \mathrm{~km}$ depth.

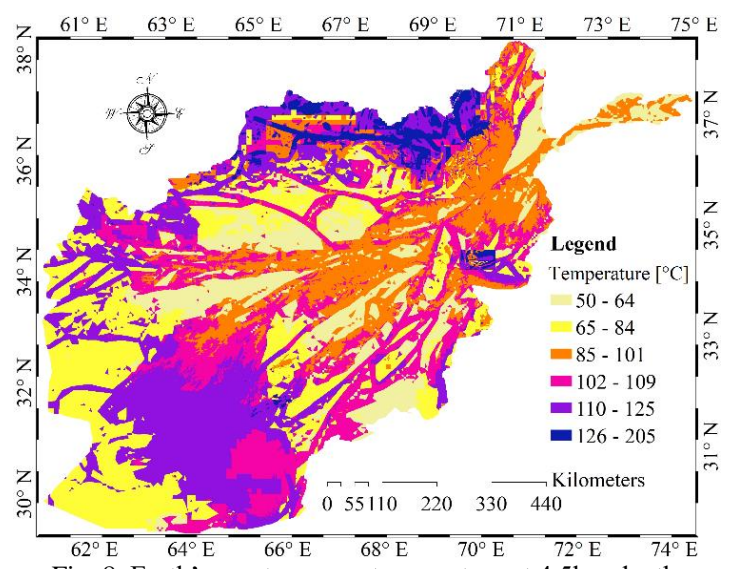

Fig. 8. Earth's crust average temperature at $4.5 \mathrm{~km}$ depth. 


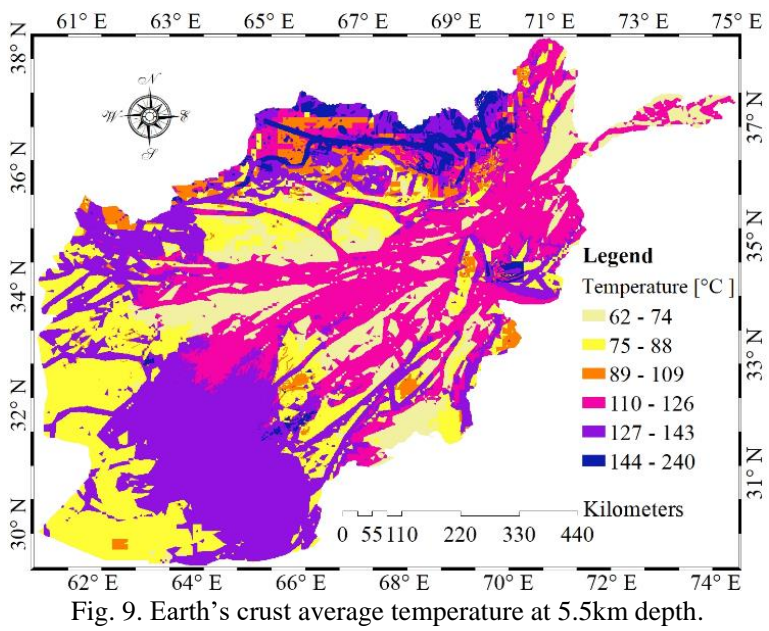

Fig.10-14 shows the average temperature from 6.5 to 10.5 $\mathrm{km}$ in earth's crust of Afghanistan. The shallow Curie point $\left(580^{\circ} \mathrm{C}\right)$ isothermal region of the crust which is located in Helmand- Arghandab also may have the higher temperature. This region is the prospect area for geothermal energy power generation. The temperature of $75 \%$ in the country earth's crust would be reasonable for the geothermal power generation either in hydrothermal or dry hot rocks systems.

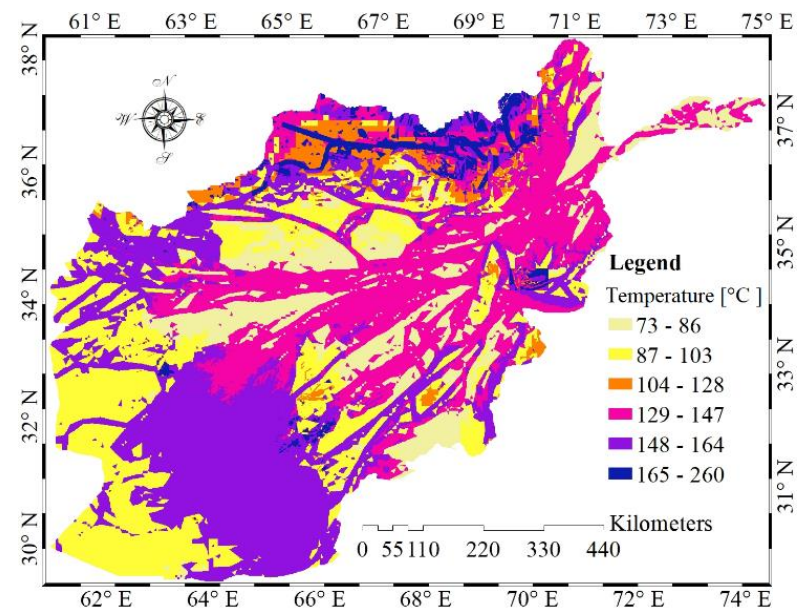

Fig. 10. Earth's crust average temperature at $6.5 \mathrm{~km}$ depth.

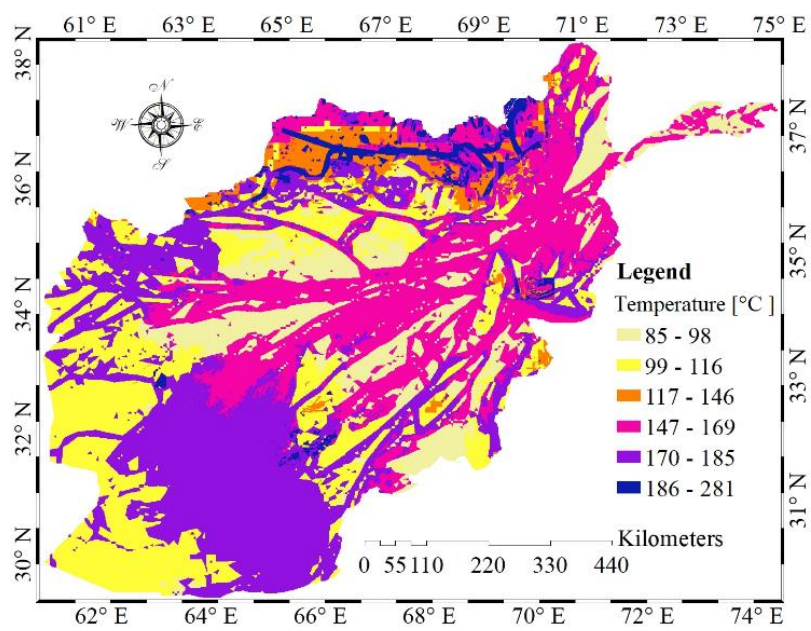

Fig. 11. Earth's crust average temperature at $7.5 \mathrm{~km}$ depth.

EGS installation is almost possible in the whole country at the depth of 6.5 to $10.5 \mathrm{~km}$. Notably, around fault systems, and in prospect areas for geothermal energy resources. However, the EGS technology deployment would be not accessible in the current situation. Until $5 \mathrm{~km}$, the application of the hydrothermal system are the best options for power production. Also, the shallow temperature could be used for district heating, food production, and in industry.

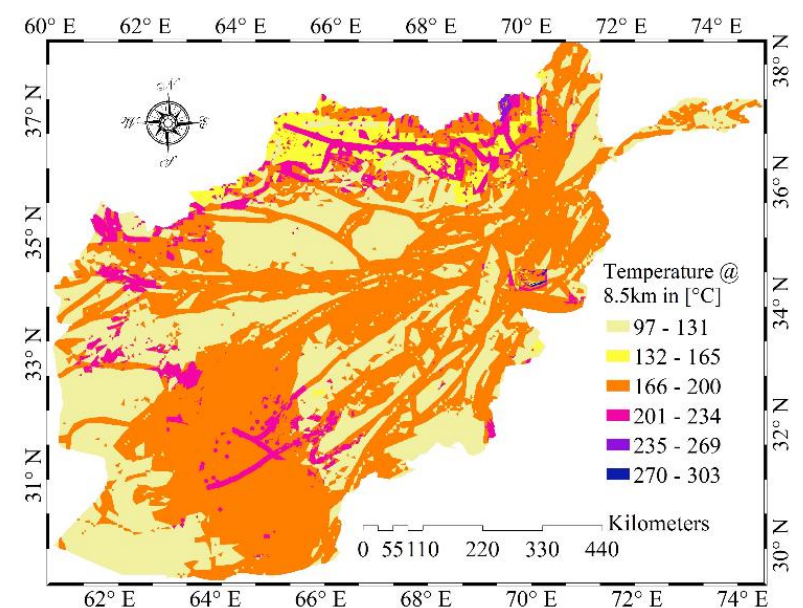

Fig. 12. Earth's crust average temperature at $8.5 \mathrm{~km}$ depth.

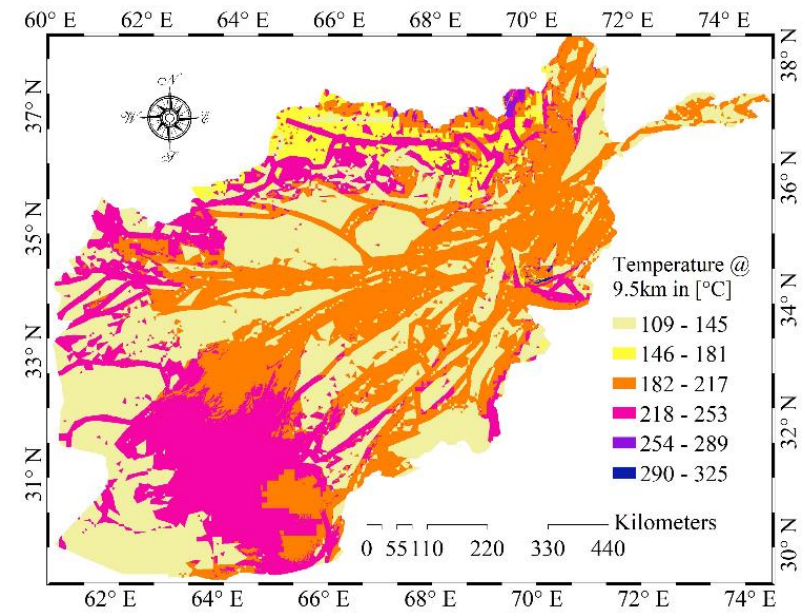

Fig. 13. Earth's crust average temperature at $9.5 \mathrm{~km}$ depth.

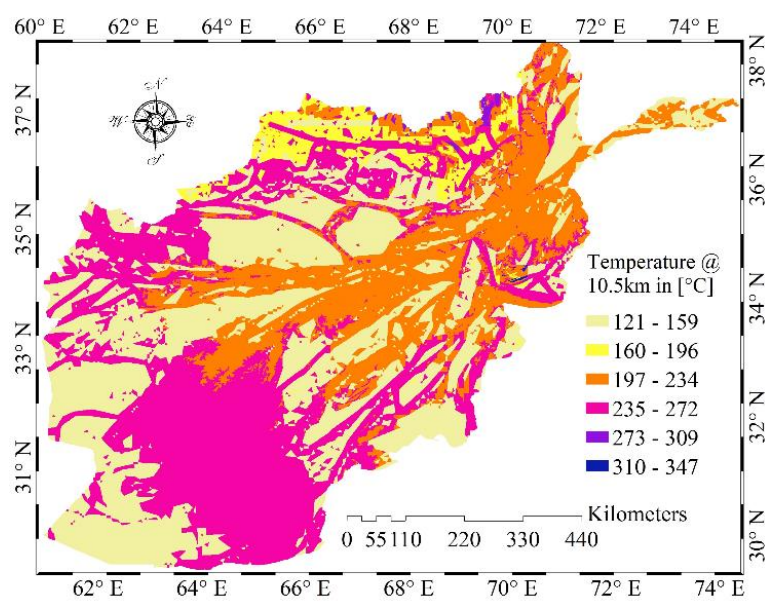

Fig. 14. Earth's crust average temperature at $10.5 \mathrm{~km}$ depth.

\section{CONCLUSION}

The analyses show that there is enormous stored heat in the underground rocks. The geothermal prospect areas in Helmand, Maqur-Chaman fault, Kabul basin, Amu basin, Arghandab basin and Herat may have an average temperature above $90{ }^{\circ} \mathrm{C}$ in the depth of $3.5 \mathrm{~km}$. However, at a depth of $5 \mathrm{~km}$, the entire known geothermal fields of the country would have a temperature in the range of $100 \sim 240{ }^{\circ} \mathrm{C}$, 
which is technically reasonable for power production. With GIS it is possible to analyze the earth's crust temperature and other related parameters optimistically. The proposed model and GIS techniques have the ability to estimate the temperature at any depth of the crust. The method also has the capability to optimize the input layers and parameters for the further improved result. In this study, we have mapped the earth's crust thickness, surface temperature, surface heat flow, mantle heat flow, and sediment thickness to analyze the possible average temperature in Afghan's land crust at a depth of 3.5 to $10.5 \mathrm{~km}$. All these plots are the first digital maps, they are estimated on the base of either measurement (airborne, gravity, and field) or evidence (geological, geophysical, and geochemical). Some of the input layers or a part of the maps in the analysis are on the base of either estimation or geological evidence. It has been suggested that the field measurement should be carried out in the most feasible geothermal fields to define the accuracy of the maps. The field measurement of earth surface (groundwater) temperature, surface heat flow, thermal conductivity, would be more helpful for further improvement. Moreover, for the future research, the radioactive heat generation should be studied in the crust to determine the potassium, uranium, and thorium heat generation relation in different lithology of the crust.

\section{ACKNOWLEDGEMENT}

I would like to appreciate Dr. William D. Gosnold, Jr (a distinguished professor of Geology and Geological Engineering at University of North Dakota) regarding his helpful advice and sharing of useful book name to initiate this study and design a reasonable model for earth's crust temperature calculation.

\section{REFERENCES}

[1] S. Ingrid and K. Bucher, "Geothermal energy," Germany: Springer-Verlag Berlin Heidelberg, pp. 2-12.

[2] D. S. Saba et al., "Geothermal energy in Afghanistan: Prospects and potential," Afghanistan Center for Policy and Development Studies, Kabul, Afghanistan, February 2004

[3] G. Laske, Z. Ma, G. Masters, and M. Pasyanos, "Update on CRUST1.0: A 1-degree global model of Earth's crust," Geophysics. Res. Abstracts, vol. $15,2013$.

[4] NREL (National Renewable Energy Laboratory). Afghanistan Resource Maps and Toolkit. [Online]. Available: http://www.nrel.gov/international/ra_afghanistan.html

[5] KPU (Kabul Poly Technique University), Department of Geological Exploration and Extraction of Minerals, 2013.

[6] AGS (Afghanistan Geological Survey), Geological Map of Afghanistan, Scale: 1:500 000 Ministry of Mining and Industry of Afghanistan, 1977.

[7] USGS (United State Geological Survey). (2015). Afghanistan geology database and GIS maps. [Online]. Available: http://afghanistan.cr.usgs.gov/geospatial-reference-datasets

[8] B. David, "A Hydrogeological Atlas of Faryab Province, Northern Afghanistan," 2014.

[9] H. Saibi, E. Aboud, and J. Gottsmann, "Curie point depth from spectral analysis of aeromagnetic data for geothermal reconnaissance in Afghanistan," Journal of African Earth Sciences, vol. 111, 2015, pp. 92-99.

[10] M. A. Anwarzai and K. Nagasaka, "Prospect area mapping for geothermal energy exploration in Afghanistan," Journal of Clean Energy Technology, vol. 5, no. 6, 2017, pp. 501-506.
[11] M. A. Anwarzai and K. Nagasaka, "Estimating earth surface mean heat flow in Afghanistan by thermo-tectonic age and geological setting with GIS multi-criteria decision analysis," 2017.

[12] J. W. Tester et al., "The future of geothermal energy: Impact of enhanced geothermal systems (EGS) on the United States in the 21st century," Massachusetts Institute of Technology, vol. 209, 2006.

[13] M. Makiko et al., "Measurement of radioactive heat generation in rocks by means of gamma ray spectrometry," in Proc. the Japan Academy, Series B 75, no. 7, 1999, pp. 181-185.

[14] J. W. Tester et al., "A well by well method for estimating surface heat flow for regional geothermal resource assessment," in Proc. Thirty-Seventh Workshop on Geothermal Reservoir Engineering, Stanford, SGP-TR-194, 2012.

[15] M. Peters et al., "Predicting gravity and sediment thickness in Afghanistan,” Geophysical Journal International, vol. 192, no. 2, 2012, pp. 586-601.

[16] S. Hakim et al., "Structural investigations of Afghanistan deduced from remote sensing and potential field data," Acta Geophysica, vol. 64, no. 4, 2016, pp. 978-1003.

[17] L. Gabi, "A global digital map of sediment thickness," Eos Trans., vol. 78, 1997.

[18] J. R. Johnson et al., "Heat flow from the Earth's interior: Analysis of the global data set," Reviews of Geophysics, vol. 31, no. 3, 1993, pp. 267-280.

[19] D_Galson et al., "The heat flow through oceanic and continental crust and the heat loss of the Earth," Reviews of Geophysics, vol. 18, no. 1, 1980, pp. 269-311.

[20] H. N. Pollack et al., "Global heat flow: A new look," Earth and Planetary Science Letters, vol. 28, no. 1, 1975, pp. 23-32.

[21] N. Younes et al., "GIS integration model for geothermal exploration and well sitting," Geothermics, vol. 37, no. 2, 2008, pp. 107-131.

[22] C. Jaupart et al., "7.06-temperatures, heat, and energy in the mantle of the earth," Treatise on Geophysics, vol. 7, 2007, pp. 223-270.

[23] E. Huenges, "Geothermal energy systems_exploration, development, and utilization," WILEY-VCH Verlag GmbH \& Co. KGaA, Weinheim, pp. 6-7, 37, 83-85, 2010.

[24] M. J. Thomas et al., "Hydrogeology and water quality of the Chakari Basin, Afghanistan,” No. 2014-5113, US Geological Survey, 2014.

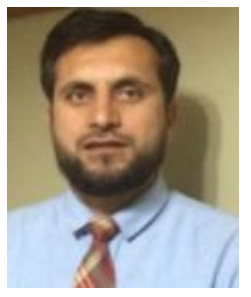

Mohammad Abed Anwarzai received his B.S degree in electrical and electronic from Kabul University in 2004, and the master degree in electrical and electronic from Tokyo University of Agriculture and Technology in March 2015. Since April 2015, he is working toward his $\mathrm{Ph} . \mathrm{D}$. degree in the Department of Electronic and Information Engineering of Tokyo University of Agriculture and Technology, Tokyo, Japan. His interest research is on renewable energies development for Afghanistan. Particularly, solar, wind, and geothermal energies potential. He had worked as telecom engineer in AWCC and Roshan of Afghanistan since 2005 to 2008 . He had been employed as power distribution design engineer in Afghan Electric Power Company (AEPC) since 2009 to 2010 . He became senior electrical engineer in UNOPS (United Nation Office for Project Services) of Afghanistan (2010-Sep, 2011).

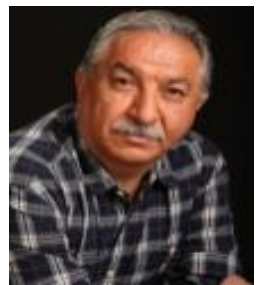

Ken Nagasaka obtained his Ph.D. in electrical engineering from Tokyo Metropolitan University (1990). He became a chief researcher at CSD Company, Tokyo (1990-1991). He became a visiting professor at University of Manitoba, Winnipeg, Canada (1991-1994). He worked as a scientist at Central Research Institute of Electric Power Industry, Tokyo (1994-1998). He became an associate professor in the Department of Electrical Engineering of Tokyo Metropolitan University (1995-1998). Since 1998 he taught and researched at the Graduate School of Engineering, Tokyo University of Agriculture and Technology. Currently, he is a Professor of Tokyo University of Agriculture and Technology. Prof. Nagasaka has published more than 600 papers in the area of power systems and renewable energies. 